\title{
EFEITO INIBITÓRIO DO ÓLEO ESSENCIAL DO Eucalyptus sp., PURO E ASSOCIADO A ANTIBIÓTICOS, FRENTE A CEPAS DE Escherichia coli e Staphylococcus aureus ISOLADAS DE MANIPULADORES, ALIMENTOS, AREIA E ÁGUA DO MAR
}

\author{
ADENILDE RIBEIRO NASCIMENTO* \\ JOSILENE LIMA SERRA** \\ ANDRÉ GUSTAVO LIMA DE ALMEIDA MARTINS*** \\ JOÃO ELIAS MOUCHREK FILHO* \\ NATANAEL EUDES ARAGÃO**** \\ LIANA SOUZAANDRADE ${ }^{\star \star \star \star \star ~}$
}

\begin{abstract}
O óleo essencial obtido das folhas do Eucalyptus sp. foi avaliado quanto à atividade inibitória frente a diferentes cepas de Escherichia coli e Staphylococcus aureus, bem como verificado o possível efeito sinérgico da associação entre o óleo essencial e antibióticos. Para a avaliação qualitativa e quantitativa da atividade antibacteriana de óleos essenciais e antibióticos comerciais foram aplicados os métodos de difusão de disco e diluição em caldo, respectivamente. Os resultados obtidos evidenciaram que o óleo essencial de Eucalyptus sp. apresentou maior potencial inibitório frente à cepa de $S$. aureus isolada de sururu (Mytella falcata). Não se verificou efeito sinérgico da associação dos antibióticos com o óleo essencial de Eucalyptus sp. sobre bactérias multirresistentes. O óleo essencial das folhas do Eucalyptus sp. apresentou potencial bacteriostático, podendo representar alternativa para a terapia à base de produtos naturais. Contudo, estudos mais detalhados sobre a toxicidade do eucalipto devem ser realizados.
\end{abstract}

PALAVRAS CHAVE: Eucalyptus sp.; ÓlEO ESSENCIAL; ANTIBIÓTICOS.

\footnotetext{
* Professores, Departamento de Tecnologia Química, Pavilhão Tecnológico, Universidade Federal do Maranhão (UFMA), São Luís, MA (e-mails: adenild@bol.com.br; mouchrek@ufma.br).

** Especialista em tecnologia de Alimentos, UFMA, São Luis, MA (e-mail: Is josy@yahoo.com.br).

*** Doutor em Ciência e Tecnologia de Alimentos, UFMA, São Luis, MA (e-mail: andremartins1975@yahoo.com.br).

**** Químico Industrial, UFMA, São Luis, MA (e-mail: natanaelaragao@hotmail.com).

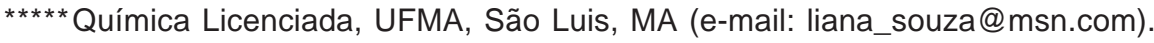




\section{INTRODUÇÃO}

A relação da humanidade com produtos naturais é tão antiga quanto a sua própria existência, sendo especialmente intensa com as plantas aplicadas para fins nutricionais e terapêuticos. Por longo período de tempo, as plantas têm sido uma das fontes de produtos naturais para a manutenção da saúde humana (ARAÚJO e LEON, 2001). Porém, desde o advento da Revolução Industrial e o desenvolvimento da química orgânica, a preferência por produtos sintéticos para o tratamento farmacológico quase extinguiu o uso de derivados de plantas como antimicrobiano (COWAN, 1999; NASCIMENTO, 2004).

As indústrias farmacêuticas produziram e desenvolveram imensa variedade de antibióticos. $O$ consumo de mais de uma tonelada diária de antibióticos em alguns países da Europa tem resultado na resistência de populações bacterianas, causando sério problema de saúde pública (RAPINI et al., 2004).

Em decorrência do problema de resistência microbiana, a busca por novas substâncias antimicrobianas a partir de produtos naturais tem aumentado o interesse das companhias farmacêuticas, principalmente por espécies de plantas utilizadas na medicina popular no combate a doenças, como resfriados, bronquites, gastrenterites, diarréias e infecções urinárias, entre outras. As propriedades antimicrobianas de substâncias presentes em extratos e óleos essenciais produzidos pelas plantas, como consequência do seu metabolismo secundário, também são reconhecidas empiricamente há séculos. No entanto, somente nos últimos anos foram comprovadas cientificamente (AHMAD e BEG, 2001; BUR e REINDERS, 2003; PEREIRA et al., 2004).

O estudo sobre plantas aromáticas no Brasil é bastante extenso e o número de plantas conhecidas para a produção de óleos essenciais abrange desde plantas rasteiras, como a hortelã, até plantas de porte arbóreo, como é o caso do eucalipto (VITTI e BRITO, 2003).

O Eucalipto tornou-se uma das plantas mais cultivadas do mundo em razão de suas aplicações nas indústrias farmacêuticas, de perfumaria, na extração de madeira e produção de papel. Diversas espécies dessa planta são bastante utilizadas na medicina tradicional da China para várias situações médicas (CHENG et al., 2008).

Baseado nos conhecimentos empíricos da medicina popular, diversos estudos tem sido reportados na literatura sobre as propriedades químicas, biológicas e medicinais do óleo essencial do eucalipto, tais como a sua atividade antimicrobiana (ESTANISLAU et al., 2001), larvicida (NATHAN, 2007), analgésica e antiinflamatória (SILVA et al., 2003).

O objetivo dessa pesquisa foi avaliar a ação antibacteriana do óleo essencial extraído das folhas do Eucalyptus sp. frente a cepas de Escherichia coli e Staphylococcus aureus.

\section{MATERIAL E MÉTODOS}

\subsection{MATERIAL BOTÂNICO}

As folhas do Eucalyptus sp. foram coletadas no comércio informal da cidade de São Luís (MA), no período de julho a outubro de 2007. O material coletado foi mantido à temperatura ambiente, sem exposição à luz solar e em local seco para que ocorresse sua desidratação. Após a secagem, as folhas foram moídas em moinho elétrico.

\subsection{EXTRAÇÃO DO ÓLEO ESSENCIAL}

O óleo essencial foi extraído pelo processo de hidrodestilação, utilizando-se o sistema de Clevenger no Laboratório de Físico-Química do Programa de Controle de Qualidade de Alimentos e Água da Universidade Federal do Maranhão (UFMA). Para a obtenção do óleo foram utilizadas $300 \mathrm{~g}$ das folhas secas e moídas, diluídas em água destilada na proporção de 1:10, as quais foram submetidas 
à temperatura de $100^{\circ} \mathrm{C}$ por 3 horas. Posteriormente, o óleo extraído foi seco por meio da percolação em sulfato de sódio anidro.

\subsection{ISOLAMENTO E IDENTIFICAÇÃO DAS CEPAS TESTES DE Staphylococcus COAGULASE POSITIVA E Escherichia coli}

As cepas de S. aureus e E. coli foram isoladas de humanos (manipuladores de alimentos), alimentos (alface e sururu) e ambiente (areia e água do mar) durante os meses de novembro de 2007 a fevereiro de 2008 no Laboratório de Microbiologia da UFMA. Para o isolamento e identificação de Escherichia coli dos alimentos foram utilizadas, respectivamente, as técnicas descritas no Compendium of methods for the microbiological examination of foods (VANDERZANT e SPLITTSTOESSER, 2001) e Sistema API 20E (BIOMÉRIEUX, 1997).

Para o isolamento do Staphylococcus coagulase positiva e Escherichia coli dos manipuladores de alimentos empregou-se a técnica do swab, com plaqueamento em Agar Baird-Parker e Ágar Eosina Azul de Metileno, segundo a metodologia descrita por Lancette e Bennett (2001).

A Escherichia coli foi isolada da água do mar mediante plaqueamento direto, usando-se Violeta Red Bile Agar como meio seletivo. Inoculou-se $0,1 \mathrm{~mL}$ da amostra na superfície do ágar, que foi espalhado com auxílio de alça de Drigalski (APHA, 2005). Após o período de incubação $\left(35^{\circ} \mathrm{C} / 24\right.$ horas), as cepas foram identificadas pelo Sistema API 20E (BIOMÉRIEUX, 1997).

Para o isolamento do Staphylococcus coagulase positiva da areia da praia, $25 \mathrm{~g}$ da amostra foi diluída em $225 \mathrm{~mL}$ de solução salina $0,85 \%$ de $\mathrm{NaCl}$ (diluição $1^{-1}$ ). A partir dessa diluição foram feitas diluições decimais sucessivas $10^{-2}$ e $10^{-3}$. Em seguida, inoculou-se $0,1 \mathrm{~mL}$ de cada diluição em Agar Baird-Parker com posterior incubação a $35^{\circ} \mathrm{C}$ por 24 horas. As colônias suspeitas de $S$. aureus foram isoladas e identificadas pelos testes de coloração de Gram, catalase e coagulase em plasma de coelho (VANDERZANT e SPLITTSTOESSER, 2001).

\subsection{SUSCEPTIBILIDADE DAS CEPAS AO ÓLEO ESSENCIAL}

Avaliou-se a atividade antibacteriana do óleo essencial por meio dos métodos de difusão de disco e de microdiluição em caldo (NCCLS, 2003; CLSI, 2009). Para a realização dos referidos experimentos "in vitro", as cepas testes de E. coli e S. aureus foram ativadas em Caldo Brain Heart Infusion (BHI) e incubadas durante 24 horas a $35^{\circ} \mathrm{C}$. Após este subcultivo procedeu-se à padronização do inóculo, que consistiu na preparação de suspensão bacteriana em solução salina $0,85 \%$ de $\mathrm{NaCl}$,

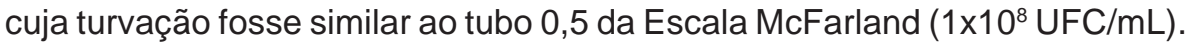

Para a determinação da atividade inibitória do óleo essencial de Eucalyptus sp. frente às cepasteste foram utilizados, como parâmetros, os padrões de sensibilidade adotados por Moreira et al. (2005) que classificaram a atividade de diferentes óleos essenciais de acordo com o tamanho do halo de inibição: não sensível (-) para diâmetros $\leq 8 \mathrm{~mm}$; sensível (+) para diâmetros de 9-14 mm; muito sensível (++) para 15-19 mm e extremamente sensível (+++) para os halos com diâmetros $\geq 20 \mathrm{~mm}$.

\subsection{SUSCEPTIBILIDADE DAS CEPAS AOS ANTIBIÓTICOS COMERCIAIS}

Usou-se o método de difusão de discos (CLSI, 2009) para testar o comportamento das cepas de $E$. coli e $S$. aureus coagulase positiva frente à ação dos seguintes antibióticos comerciais: Ácido pipemídico - $20 \mu \mathrm{g}$, Tetraciclina - $30 \mu \mathrm{g}$, Ampicilina - $10 \mu \mathrm{g}$, Vancomicina - $15 \mu \mathrm{g}$.

\subsection{AVALIAÇÃO DO EFEITO SINÉRGICO DAASSOCIAÇÃO DE ANTIBIÓTICOS COMERCIAIS E O ÓLEO ESSENCIAL DE Eucalyptus sp.}

A avaliação da combinação entre o óleo essencial e os antibióticos comerciais foi realizada pela técnica de difusão. Os discos contendo os antibióticos foram embebidos com $20 \mu \mathrm{L}$ da menor 
concentração inibitória do óleo, sendo em seguida colocados em placas de Petri estéreis contendo o Ágar Muller Hinton inoculado com 0,1 mL da cultura bacteriana, conforme a metodologia recomendada por Oliveira et al.(2006).

\section{RESULTADOS E DISCUSSÃO}

A Tabela 1 apresenta os valores dos halos de inibição $(\mathrm{mm})$ referentes à atividade antibacteriana e à concentração inibitória mínima (CIM) observados para as cepas de Escherichia coli e Staphylococcus aureus, isoladas de diferentes fontes e para cepas padrão frente à ação do óleo essencial do Eucalyptus sp.

\section{TABELA 1 - HALOS DE INIBIÇÃO E CONCENTRAÇÃO INIBITÓRIA MÍNIMA DO ÓLEO ESSENCIAL DE Eucalyptus sp. FRENTE ÀS CEPAS S. aureus E E.coli}

\begin{tabular}{l|c|c}
\hline \multirow{2}{*}{\multicolumn{1}{c|}{ CEPAS }} & \multicolumn{2}{c}{ Óleo essencial de Eucalyptus sp. } \\
\cline { 2 - 3 } & Halo de inibição (mm) & CIM (mg/mL) \\
\hline E.coli ATCC 25922 & $13(\mathrm{~S})$ & 8 \\
\hline E.coli (Alface) & $8(\mathrm{R})$ & 64 \\
\hline E.coli (Água do mar) & $7(\mathrm{R})$ & 16 \\
\hline E.coli (Manipulador de alimento) & $7(\mathrm{R})$ & 8 \\
\hline S.aureus ATCC 12600 & - & - \\
\hline S.aureus (Manipulador de alimento) & $7(\mathrm{R})$ & - \\
\hline S.aureus (Sururu) & $15(\mathrm{~S})$ & 32 \\
\hline S.aureus (Areia do mar) & $7(\mathrm{R})$ & 8 \\
\hline
\end{tabular}

Nota: CIM - Concentração inibitória mínima, S - sensível, R - resistente, (-) - sem inibição.

De acordo com a Tabela 1, os halos de inibição encontrados variaram de 7 a $15 \mathrm{~mm}$ de diâmetro, considerando todas as cepas bacterianas testadas. Os resultados evidenciaram que somente a cepa de $E$. coli padrão e $S$. aureus isolado de sururu foram sensíveis à ação do óleo essencial de eucalipto, com halos de inibição de 13 e $15 \mathrm{~mm}$, respectivamente.

Estanislau et al. (2001) ao estudarem a ação antibacteriana de cinco espécies de eucalipto, cultivadas em Goiás, reportaram a eficiência da ação dos óleos de eucalipto frente às bactérias gram negativas, inclusive a E. coli. Resultados similares foram encontrados por Cimanga et al. (2002) ao investigarem a atividade antibacteriana de 15 plantas medicinais na República Democrática do Congo, das quais 10 espécies pertenciam ao gênero Eucalyptus. Demonstraram que os óleos essenciais de Eucalyptus foram mais eficientes frente a $E$. coli do que a S. aureus. Os halos de inibição encontrados para $E$. coli variaram de 7 a $20 \mathrm{~mm}$, enquanto que $S$. aureus foi resistente à maioria dos óleos aplicados. Tais resultados estão de acordo com os dados encontrados nesta pesquisa, uma vez que todas as cepas de E. coli foram inibidas pela ação do óleo testado e somente a cepa de $S$. aureus padrão mostrou-se resistente.

Segundo Batish et al. (2008), a bioatividade dos óleos essenciais de eucalipto pode estar diretamente correlacionada com a sua composição química, que apresentam como componentes majoritários: 1,8 cineol, citronelal, citronelol, p-cimeno, limoneno, linalol, $\alpha$-pineno, $\gamma$-terpineno e $\alpha$ terpineol. Contudo, a qualidade e quantidade dessas substâncias podem variar de acordo com o estágio de crescimento da planta, condições ecológicas e método utilizado para a extração do óleo essencial (MOREIRA et al., 2005). 
A menor concentração inibitória encontrada foi de $8 \mathrm{mg} / \mathrm{mL}$ para a cepa de $E$. coli padrão, $E$. coli isolada de humanos e $S$. aureus isolado do ambiente. As demais cepas foram sensíveis a pelo menos uma das concentrações aplicadas do óleo, com exceção das cepas de $S$. aureus padrão e $S$. aureus isolada de humanos. É importante ressaltar que apesar do baixo espectro de ação do óleo essencial de eucalipto durante a sua aplicação puro, esse apresentou níveis significativos de inibição quando diluído.

Chagas et al. (2002) afirmaram que os óleos emulsificavéis (diluídos) apresentam maior bioatividade do que os aplicados de forma natural (puro) porque quando utilizado puro, o óleo é somente lipolítico implicando em menor absorção. O concentrado emulsificado é lipolítico e hidrofílico devido dispersão nas moléculas do óleo pela ação do tensoativo, permitindo maior biodisponibilidade de monoterpenos sobre os microrganismos. Deve-se ressaltar que o método de difusão em ágar para a determinação de antibiogramas não é específico para óleos essenciais, o que pode influenciar sua difusibilidade (PEREIRA et al., 2008).

Hammer, Carson e Riley (1999) também demonstraram a susceptibilidade das cepas de $E$. coli e S. aureus nas concentrações de $1 \%$ e $2 \%$, respectivamente, frente ao óleo essencial de Eucalyptus polybractea, popularmente conhecido como eucalipto. No entanto, enfatizaram que pesquisas posteriores deveriam ser realizadas, principalmente, sobre as propriedades tóxicas e irritantes desse óleo. Cermelli et al. (2008) ao investigarem a ação antimicrobiana do óleo essencial do eucalipto encontraram resultados semelhantes ao desta pesquisa, tanto pelo método de difusão de discos quanto pelo método de diluição em caldo.

Na Tabela 2 são apresentados os resultados referentes à sensibilidade das cepas de $E$. coli e S. aureus aos antibióticos comerciais. As cepas-teste de S. aureus apresentaram resistência a pelo menos um dos antibióticos testados. No que diz respeito às cepas-teste de $E$. coli, a isolada de alimentos demonstrou-se resistente a todos os antibióticos comerciais aplicados, enquanto que a isolada de ambiente mostrou-se resistente somente à ampicilina. É importante ressaltar a diferença na resistência das cepas de Escherichia coli e Staphylococcus aureus isoladas de diferentes origens aos antibióticos comerciais. Algumas bactérias podem diferir na sua resistência intrínseca, ou desenvolver a resistência a antibióticos quando submetidas a diferentes condições ambientais.

\section{TABELA 2 - SENSIBILIDADE DAS CEPAS DE S.aureus E E.coli DETECTADA PELO MÉTODO DE DIFUSÃO DE DISCOS FRENTE A AGENTES ANTIMICROBIANOS COMERCIAIS}

\begin{tabular}{l|c|c|c|c}
\hline \multirow{2}{*}{\multicolumn{1}{c|}{ CEPAS }} & \multicolumn{4}{c}{ Antibióticos } \\
\cline { 2 - 5 } & PIP & TET & AMP & VAN \\
\hline E.coli ATCC 25922 & $20(\mathrm{~S})$ & $19(\mathrm{~S})$ & $19(\mathrm{~S})$ & NT \\
\hline E.coli (Alface) & - & $9(\mathrm{R})$ & $9(\mathrm{R})$ & NT \\
\hline E.coli (Água do mar) & $20(\mathrm{~S})$ & $12(\mathrm{I})$ & - & NT \\
\hline E.coli (Manipulador de alimento) & $16(\mathrm{I})$ & $26(\mathrm{~S})$ & $30(\mathrm{~S})$ & NT \\
\hline S.aureus (Manipulador de alimento) & NT & NT & $31(\mathrm{~S})$ & $13(\mathrm{R})$ \\
\hline S.aureus ATCC 12600 & NT & NT & - & $17(\mathrm{~S})$ \\
\hline S.aureus (Sururu) & NT & NT & - & $15(\mathrm{~S})$ \\
\hline S.aureus (Areia da praia) & NT & NT & $30(\mathrm{~S})$ & $13(\mathrm{R})$ \\
\hline
\end{tabular}

Nota: PIP = Ácido pipemídico, TET = Tetraciclina, AMP = Ampicilina, VAN = Vancomicina, $(-)=$ sem halo de inibição, S = sensível, I = Intermediário, R = Resistente, NT = Não Testada.

Nascimento et al. (2007) compararam a ação dos antibióticos convencionais e óleos essenciais frente a bactérias isoladas de sururu, inclusive $E$. coli e $S$. aureus, bem como seus respectivos controles padrão ATCC. Os resultados demonstraram que ambas as cepas de E. coli foram sensíveis à tetraciclina 
e ao ácido pipemídico. No entanto, somente a cepa de S. aureus ATCC 25923 foi sensível à vancomicina, sendo a cepa de Staphylococcus coagulase positiva isolada de sururu resistente à vancomicina e à ampiclina. Esses dados corroboram os resultados encontrados nesta pesquisa.

A presença de cepas de $S$. aureus resistentes à vancomicina em manipuladores de alimentos tornou-se problema preocupante para a saúde pública, uma vez que a manipulação inadequada ou sem o devido controle higiênico-sanitário pode acarretar a contaminação de alimentos por esses patógenos. Rapini et al. (2004) estudaram o perfil de resistência de 45 cepas de Staphylococcus sp. isoladas de queijo tipo coalho e constataram que $75,5 \%$ foram resistentes à vancomicina. Dessas $90,9 \%$ eram cepas de S. aureus, $100 \%$ de Staphylococcus coagulase positiva e $43,8 \%$ de Staphylococcus coagulase negativa.

Em relação à associação entre antibióticos comerciais e o óleo essencial de eucalipto, observou-se que o óleo não interferiu na ação dos antimicrobianos comerciais testados. Os resultados para a ação inibitória do antibiótico associado ao óleo essencial foram semelhantes aos obtidos pela utilização dos antibióticos isolados. Os estudos sobre o efeito sinérgico entre óleos essenciais e drogas ineficazes na antibioticoterapia têm se intensificado, visando melhorar o seu espectro de ação (HARRIS, 2002).

Nascimento et al. (2000) obtiveram êxito ao associarem antibióticos e extratos vegetais ou fito fármacos, demonstrando que em alguns casos ocorreu sinergismo. Entretanto, é importante ressaltar que o uso paralelo de plantas medicinais e/ou seus subprodutos com medicamentos convencionais pode inibir ou intensificar seu efeito terapêutico, bem como não interferir na resposta esperada.

\section{CONCLUSÃO}

A avaliação da atividade antibacteriana pelo método de difusão de discos indicou qualitativamente que o óleo essencial do Eucalyptus sp. apresentou ação bacteriostática sobre o crescimento das cepas de Escherichia coli e Staphylococcus aureus. Não foi verificado o efeito sinérgico da associação entre antibióticos comerciais e o óleo essencial de Eucalyptus sp frente à Escherichia coli e Staphylococcus aureus.

\section{ABSTRACT \\ INHIBITORY EFFECT OF Eucalyptus sp. ESSENTIAL OIL, PURE AND IN ASSOCIATED TO ANTIBIOTICS, AGAINST STRAINS OF Escherichia coli AND Staphylococus aureus ISOLATED FROM HANDLERS, FOOD, SAND AND SEAWATER}

The essential oil obtained from the Eucalyptus sp. leafs was evaluated according to the inhibitory activity against different strains of Escherichia coli and Staphylococus aureus. It was also verified the possibility of synergistic effect of the association among essential oil and antibiotics. To evaluate the antibacterial effect of commercial antibiotics and essential oil were applied the disc diffusion method and the dilution in stock method. The results showed that the essential oil of Eucalyptus sp. presented higher inhibitory potential against the strains of $S$. aureus isolated from Mytella falcata. It was not verified synergism from the association among antibiotics and essential oil of Eucalyptus sp. against multi-resistant bacterias. The antibacterial activity of the Eucalyptus sp. observed revalidate the importance of this plant to the alternative therapy based in natural products. However studies concerning the toxicity of Eucalyptus sp. should be intensified.

KEY-WORDS: Eucalyptus sp.; ESSENTIAL OIL; ANTIBIOTICS.

\section{REFERÊNCIAS}

1 AHMAD, I.; BEG, A.Z. Antimicrobial and phytochemical studies on 45 Indian medicinal plants against multi-drug resistant human pathogens. Journal of Ethnopharmacology, v.74, n.2, p.113-123, 2001. 
2 AMERICAN PUBLIC HEALTH ASSOCIATION (APHA). Standard methods for the examination of water and wasterwater, $21^{\text {th }}$. ed. Washington, 2005.

3 ARAÚJO, C.A.C.; LEON L.L. Biological activities of Curcuma longa L. Memórias do Instituto Oswaldo Cruz, v. 96, p.723-728. 2001.

4 BATISH, D. R.; SINGH, H. P.; KOHLI, R. K.; KAUR, S. Eucalyptus essential oil as a natural pesticide. Forest Ecology and Management, v. 256, p. 2166- 2174, 2008.

5 BIOMÉRIEUX. Salmonella, Escherichia coli and other Enterobacteriaceae in foods: biochemical system identification (API-20). Hazelwood, 1997.

6 BURT, S.A; REINDERS, R.D. Antibacterial of selected plant essential oils against Escherichia coli O157:H7. Letters in Apllied Microbiology, v.36, p. 162-167, 2003.

7 CERMELLI, C.; FABIO, G.; FABIO, A.; QUAGLIO, P. Effect of Ecalyptus essential oil on respiratory bacteria and virases. Curr. Microbiol., v. 56, p. 89-92, 2008.

8 CHAGAS, A.C.S.; PASSOS, W. M.; PRATES, H. T.; LEITE, R.C.; FURLONG, J.; FORTES, I.C.P. Efeito acaricida de óleos essenciais e concentrados emulsionáveis de Eucalyptus spp em Boophilus microplus. Braz. J. vet. Res. Anim. Sci., São Paulo, v. 39, n. 5, p. 247-253, 2002.

9 CHENG, S. S.; HUANG, C. G.; CHEN, Y. J.; YU, J.J.; CHEN, W. J.; CHANG, S. T. Chemical compositions and larvicidal activities of leaf essential oils from two eucalyptus species. Bioresource Technology, v. 100, p. 452-456, 2008.

10 CIMANGA, K.; KAMBU, K.; TONA, L.; APERS, S.; BRUYNE, T. D.; HERMANS, N.; TOTTÉ, J.; PIETERS, L.; VLIETINCK, A.J. Correlation between chemical composition and antibacterial activity of essential oils of some aromatic medicinal plants growing in the Democratic Republic of Congo. Journal Ethnopharmacology. n. 79, p. 213-220, 2002.

11 CLINICAL LABORATORY STANDARDS INSTITUTE. Methods for dilution antimicrobial susceptibility test for bacteria that grow aerobically. Wayne, $\mathrm{Pa}, 2009$. (Approved standard M02-A10, CLSI).

COWAN, M.M. Plant products as antimicrobial agents. Clinical Microbiology Reviews, v. 12, n. 4, p. 564-582, 1999.

13 ESTANISLAU, A.A.; BARROS, F.A.S.; PEÑA, A.P.; SANTOS, S.C.; FERRI, P.H.; PAULA, J.R. Composição química e atividade antibacteriana dos óleos essenciais de cinco espécies de Eucalyptus cultivadas em Goiás. Revista Brasileira de Farmacognosia, v.11, n.2, p.95-100, 2001.

14 HAMMER, K.A.; CARSON, C.F.; RILEY, T.V. Antimicrobial activity of essential oils and other plant extracts. Journal of Applied Microbiology, n. 86, p. 985-990, 1999.

15 HARRIS, R. Synergism in the essential oil world. The International Journal of Aromatherapy, v. 12, n. 4, p. 179186, 2002.

16 LANCETTE, G.A; BENNETT, R.W. Staphylococcus aureus and staphylococcal enterotoxins. In: COMPENDIUM of methods for the microbiological examination of foods. $3^{\text {rd }}$ ed. Washington: APHA, 2001.

17 MOREIRA, M.R; PONCE, A.G.; del VALLE, C.E.; ROURA, S.I. Inhibitory parameters of essential oils to reduce a foodbourne pathogen. LWT- Food Science and Techonology, v. 38, n.5,p.565-570, 2005.

18 NASCIMENTO, G.G.F.; LOCATELLI, J.; FREITAS, P.C.; SILVA, G.L. Antibacterial activity of plants extracts and phytochemicals on antibiotic-resistant bacteria. Brazilian Journal of Microbiology, v. 31, p. 247-256, 2000.

19 NASCIMENTO, A.R. Atividade antibacteriana de óleos essenciais frente a bactérias isoladas de sururu (Mytella falcata). 2004, 91 f. Tese (Doutorado em Microbiologia) - Universidade Federal de Lavras, Lavras/MG, 2004.

20 NASCIMENTO, A.R.; CARVALHO, E.P.; FURTADO-NETO, M.A.A.; MARTINS, A.G.L.A.; VIEIRA, R.H.S.F. Atividade antibacteriana de óleos essenciais frente a bactérias isoladas de sururu, Mytella falcata. Arquivos de Ciências do Mar, v.40, n. 2, p.47-54, 2007.

21 NATHAN, S. S. The use of Eucalyptus tereticornis Sm. (Myrtaceae) oil (leaf extract) as a natural larvicidal agent against the malaria vector Anopheles stephensi Liston Diptera: Culicidae. Bioresource Technology, v. 98, p. 18561860, 2007.

22 NATIONAL COMMITTEE FOR CLINICAL LABORATORY STANDARDS. Methods for dilution antimicrobial susceptibility test for bacteria that grow aerobically. Wayne, $\mathrm{Pa}, 2003$. (Approved standard M02-A8).

23 NATIONAL COMMITTEE FOR CLINICAL LABORATORY STANDARTS. Methods for dilution antimicrobial susceptibility tests for bacteria that grow aerobically. $6^{\text {th }}$. Ed. Wayne, $\mathrm{Pa}, 2003$. p. 1-47. (Approved standard M7-A6). 
24 OLIVEIRA, R.A.G; LIMA, E.O.; VIEIRA, W.L.; FREIRE, K.R.L.; TRAJANO, V.N.; LIMA, J.O; SOUZA, E.L; TOLEDO, M.S; SILVA-FILHO, R.N. Estudo da interferência de óleos essenciais sobre a atividade de alguns antibióticos usados na clínica. Revista Brasileira de Farmacognosia, v.16, n.1, p. 77-82, 2006.

25 PEREIRA, R.S.; SUMITA, T.C.; FURLAN, M.R.; JORGE, A.O.C.; UENO, M. Antibacterial activity of essential oils on microorganisms isolated from urinary tract infection. Revista de Saúde Pública, n.2, v.38, p 326-328, 2004.

26 PEREIRA, A.A.; CARDOSO, M.G.; ABREU, L.R.; MORAIS, A.R.; GUIMARÃ̃ES, L.G.; SALGADO, A.P.S.P. Caracterização química e efeito inibitório de óleos essenciais sobre o crescimento de Staphylococcus aureus e Escherichia coli. Ciência Agrotécnica, Lavras, v.32, p. 887-893, mai./jun.2008.

27 RAPINI, L.S.; TEIXEIRA, J.P.; MARTINS, N.E.; CERQUEIRA, M.M.O.P.; SOUZA, M.R.; PENNA, C.F.A.M. Perfil da resistência antimicrobiana de cepas de Staphylococcus sp. isoladas de queijo tipo coalho. Arq. Bras. Med. Vet. Zootec., v.56, n.1, p.130-133, 2004.

28 SILVA, J.; WORKU, A.; SOUSA, S.M.; DUARTE, V.G.; MACHADO, M.I.L.; MATOS, F.J.A. Analgesic and anti-inflammatory effects of essential oils of Eucalyptus. Journal of Ethnopharmacology, v. 89, p. 277-283, 2003.

29 VANDERZANT, C.; SPLITTSTOESSER, D.F. (eds.). Compendium of methods for the microbiological examination of foods. $3^{\text {rd }}$ ed. Washington: APHA, 2001.

30 VITTI, A.M.S.; BRITO, J.O. Óleo essencial de eucalipto. Piracicaba: ESALQ 2003. 26 p. (Documentos Florestais, 17). 